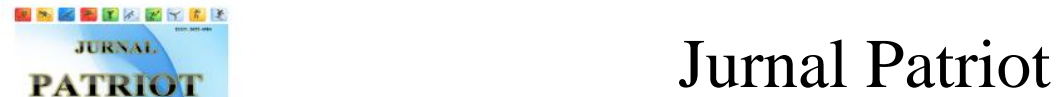

ISSN Online: 2714-6596 ISSN Cetak: 2655-4984

Home: http://patriot.ppj.unp.ac.id/index.php/patriot

Volume 3 Nomor 2 Tahun 2021 (Halaman 214-222)

DOI: $10.24036 /$ patriot.v\%vi\%i.783

\section{Profil Kebugaran Jasmani Atlet Pencak Silat Binaan Bank Sumsel Babel Palembang}

\author{
Zubaidah $^{1 *}$, Syafarudin ${ }^{2}$, Ahmad Richard Victorian ${ }^{3}$, Soleh Solahuddin ${ }^{4}$, Bayu \\ Iswana $^{5}$ \\ 1,2,3,4 Program Studi Pendidikan Jasmani dan Kesehatan, Fakultas Keguruan dan Ilmu \\ Kependidikan, Universitas Sriwijaya, Indonesia \\ ${ }^{5}$ Program Studi Pendidikan Jasman, Fakultas Keguruan dan Ilmu Pendidikan, Universitas \\ PGRI Palembang, Indonesia \\ Email Korespondensi: zubejube@gmail.com
}

Informasi Artikel:

Dikirim: 4 Mei 2021 Direvisi: 22 Juli 2021 Diterbitkan: 23 Juli 2021

\begin{abstract}
ABSTRAK
Penelitian ini bertujuan untuk mengetahui tingkat kebugaran jasmani pada atlet pencak silat binaan Bank Sumsel Babel Palembang. Jenis Penelitian ini adalah deskriptif kuantitatif. Metode yang digunakan dengan teknik pengumpulan data menggunakan observasi dan tes. Objek penelitian adalah atlet pencak silat binaan Bank Sumsel Babel Palembang yang berjumlah 7 atlet. instrumen yang digunakan untuk mengukur kebugaran jasmani menggunakan 5 etem tes yaitu tes kecepatan 20 meter, tes shuttle run, tes tiga kali lompat, tes sit up, dan tes bleep tes. Teknik analisis deskriptif dalam bentuk persentase.berdasarkan hasil penelitian yang telah dilakukan dapat diketahui bahwa kebugaran jasmani atlet pencak silat binaan Bank Sumsel Babel Palembang ada 3 orang $(42,8 \%)$ kecepatan lari 20 meter berada dalam katagori Baik, ada 7 orang $(100 \%)$ kelincahannya berada dalam katagori Sangat Baik, ada 6 orang $(85,7 \%)$ power otot tungkainya berada dalam katagori Baik, ada 7 orang ( $100 \%)$ kekuatan otot perutnya berada dalam katagori, ada 3 orang ( $42 \%$ ) daya tahannya berada dalam katagori Baik.
\end{abstract}

Kata Kunci : kebugaran jasmani, pencak silat

\section{Physical Fitness Profiles of Pencak Silat Athletes Guided by Bank Sumsel Babel Palembang}

\section{ABSTRACT}

This study aims to determine the level of physical fitness of the athletes assisted by Bank Sumsel Babel Palembang. This type of research is descriptive quantitative. The method used with data collection techniques using observation and tests. The object of the research was 7 athletes assisted by Bank Sumsel Babel Palembang. The instrument used to measure physical fitness uses 5 etem tests, namely the 20 meter speed test, the shuttle run test, the three-jump test, the sit-up test, and the bleep test. Descriptive analysis technique is in the form of a percentage. Based on the results of the research that has been done it can be seen that the physical fitness of the athletes assisted by Bank Sumsel Babel Palembang, there are 3 people (42.8\%) running speed of 20 meters is in the Good category, there are 7 people (100\%) the agility was in the Very Good category, there were 6 people (85.7\%) the leg muscle power was in the Good category, there were 7 people (100\%) the strength of the abdominal muscles was in the category, there were 3 people (42\%) the endurance was in the category. Good category.

Keywords: physical fitness, pencak silat

\section{PENDAHULUAN}

Olahraga adalah salah satu aktivitas fisik maupun psikis seseorang yang berfungsi menjaga daya tahan tubuh manusia untuk meningkatkan kesanggupan tubuh dalam 
meningkatkan kualitas kesehatan seseorang, hal ini sesuai dengan Undang-undang RI

No. 3 Tahun 2005 tentang sistem keolahragaan nasional pasal 3 dan 4 tentang fungsi dan tujuan olahraga yaitu: "keolahragaan nasional berfungsi mengembangkan kemampuan jasmani, rohani, dan sosial serta membentuk watak dan kepribadian bangsa yang bermartabat. Keolahragaan nasional bertujuan memelihara dan meningkatkan kesehatan dan kebugaran, prestasi, kualitas manusia, menanamkan nilai moral dan akhlak mulia, sportivitas, disiplin, mempererat dan membina persatuan dan kesatuan bangsa, memperkukuh ketahanan nasional, serta mengangkat harkat, martabat, dan kehormatan bangsa. Genetik berpengaruh terhadap kapasitas jantung paru, postur tubuh, obesitas, hemoglobin (sel darah merah) dan otot menurut (Amanah, 2015), menyatakan bahwa faktor-faktor yang dianggap dapat mempengaruhi kebugaran jasmani seseorang. olahraga merupakan suatu kegiatan yang bertujuan untuk memelihara dan meningkatkan kesehatan, meningkatkan kebugaran, serta olahraga juga dapat menjadi sarana untuk membina persatuan dan kesatuan bangsa, memperkukun ketahanan nasional serta mengangkat harkat dan martabat bangsa dimata dunia melalui prestasi yang diraih dalam suatu cabang olahraga. selain itu dengan berolahraga dapat meningkatkan sistem kerja jantung dan paru-paru, sehingga metabolisme tubuh berjalan dengan baik dan akhirnya memperoleh kebugaran jasmani yang bagus (Ramdani Muksin et al., 2020).

Profil secara umum dapat bisa diartikan sebagai suatu gambaran singkat tentang biografi seseorang, organisasi atau lembaga, menurut (C. Tri Juni, 2012) "profil adalah pandangan sisi, garis besar, ataupun biografi seseorang atau kelompok yang memiliki usia yang sama". Menurut (Hilman, 2016) berdasarkan undang-undang RI No. 3 Tahun 2005 pasal 1 ayat 13, "olahraga prestasi adalah olahraga yang membina dan mengembangkan olahragawan secara terencana, berjenjang, dan berkelanjutan melalui kompetisi untuk mencapai prestasi dengan dukungan ilmu pengetahuan dan teknologi keolahragaan". Dengan pembinaan olahragawan yang tepat serta di dukung dengan pemanfaatan teknologi yang baik maka untuk mencapai upaya maksimal prestasi akan lebih mudah. Ilmu pengetahuan dan teknologi sangatlah dibutuhkan oleh semua cabang olahraga, salah satunya cabang olahraga pencak silat, atlet dapat disebut lincah apabila mempunyai kemampuan untuk merubah arar dan posisi tubuh dengan cepat dan tepat pada waktu sedang bergerak, tanpa kehilangan keseimbangan dan kesadaran akan posisi tubuhnya, bentuk latihan untuk mengembangkan kelincahan tentunya adalah latihan yang mengharuskan atlet bergerak cepat dan tepat kesegala arah tanpa kehilangan keseimbangan, hal ini sesuai dengan kebutuhan masing-masing cabang olahraga (octavia \& Mardela, 2019).

Pencak silat merupakan budaya asli bangsa indonesia, induk organisasi pencak silat di indonesia adalah ikatan pencak silat indonesia (IPSI), dalam cabang pencak silat ini sangat membutuh tenaga yang prima, fisik yang prima adalah salah satu syarat dasar yang harus dimiliki oleh seorang pesilat karna dalam cabang pencak silat di katagori fighter seorang pesilat dituntut untuk melakukan tendangan, pukulan, bantingan, serkelan dan masih banyak teknik-teknik yang dilakukan dengan kecepatan dan 
ketepatan dalam waktu 3 x 2 menit, sedangkan di katagori TGR (tunggal, ganda, regu) mereka juga di tuntut untuk memperagakan gerakan tunggal, ganda, regu dengan benar, tepat, mantap, dan harus memiliki penjiwaan, dengan memperagakan secara tangan kosong dan bersenjata selama 3 menit, dengan adanya pembinaan banyak komponen yang harus diperhatikan oleh seorang pelatih supaya atlet yang saat ini dia latih atau dia bina bisa meraih prestasi yang maksimal. Komponen yang harus diperhatikan yaitu fisik, teknik, mental, taktik dan strategi, Fisik adalah salah satu komponen dasar yang sangat penting apabila seorang atlet mengalami kelelahan pada saat pertandingan akan sangat berdampak tidak baik pada hasil pertandingan yang sedang berlangsung, kudakuda adalah salah satu teknik dasar yang digunakan untuk mengawali gerak atau jurus Menurut (Astawa et al., 2017). Menurut (Kriswanto, 2015),"pencak silat adalah suatu metode beladiri yang diciptakan untuk mempertahankan diri dari bahaya yang dapat mengancam keselamatan dan kelangsungan hidup".

Tendangan menempati posisi istimewa dalam Pencak Silat, dan tendingan secara umum merupakan teknik yang sangat dominan dalam olahraga bela diri pencak silat (Amrullah Ramdani, 2015). Tubuh yang mempunyai tingkat kebugaran jasmani yang baik tidak akan mempunyai hambatan dalam melakukan aktivitas sehari-hari (Ratna, 2013). Hasil penelitian menunjukkan bahwa terdapat perbedaan rata-rata sudut kudakuda tengah antara laki-laki dengan perempuan, pada umumnya perempuan lebih flesibel dari pada laki-laki karena struktur anatomi seperti tulang belakang, tulang ekor dan otot lebih kecil pada perempuan dibandingkan dengan laki-laki (Septa Bayu et al., 2018).

Pada penelitian ini peneliti melihat salah satu tim pencak silat pada kejuaraan Dunia (KEJURDUN) di Solo dan pada kejuaran-kejuaraan Nasional lainnya. Tim ini adalah tim pencak silat binaan Bank Sumsel Babel Palembang, binaan ini adalah tempat dimana atlet-atlet yang berprestasi yang telah mengharumkan nama baik Sumatera Selatan dalam setiap kejuaraan-kejuaraan nasional maupun internasional seperti Abas Akbar adalah pelatih bank Sumsel Babel sekaligus mantan atlet Dunia yang telah memperoleh 5 mendali Emas Sea Gemes, 2 mendali Emas kejuaraan Dunia dan masih banyak lainnya. Tim pencak silat ini telah banyak dikenal dan disegani banyak orang. Pada perguruan-perguruan di Palembang ini maupun tim di luar provinsi yang ingin berpartisipasi melakukan uji coba atau try out pada tim ini.

Dalam mencapai prestasi yang maksimal pastinya seorang atlet harus memiliki kebugaran jasmani yang baik, dalam kebugaran jasmani memiliki dua faktor yaitu faktor internal dan faktor eksternal, faktor internal yaitu sesuatu yang telah ada didalam tubuh manusia bersifat menetap seperti jenis kelamin, umur, genetik dan faktor eksternal yaitu aktivitas fisik, lingkungan dan kebiasaan misalnya merokok atau mengkomsumsi alkohol. Faktor - faktor ini sangat berpengruh terhadap pengukuran kebugaran jasmani atlet tersebut, menurut Sumantri dalam (Hartati et al., 2019) Pencak silat merupakan sistem pembelaan diri yang memiliki gerakan yang melibatkan semua komponen tubuh manusia. Seorang individu dalam memperlihatkan tingkah lakunya tidak hanya dipengaruhi oleh faktor lingkungan tapi karena timbulnya energi dari dalam diri individu itu sendiri disebut juga motivasi intrinsik (Gus Hendri \& Aziz, 2020). Pandemi Covid-19 yang melanda Indonesia yang terdeteksi pertama kali pada tanggal 2 maret 
2020 memberikan pengaruh yang sangat besar bagi masyarkat indonesia sehingga tidak bisa melakukan aktifitas seperti biasanya, hal ini juga berimbas pada atlet pencak silat karena banyak pertandingan-pertandingan yg di tunda pelaksanaannya dan kegiatan latihan pun di tiadakan yang membuat kebugaran jasmani atlet menurun.

\section{METODE}

Menurut (Sugiyono, 2010) "berpendapat bahwa variabel penelitian adalah suatu atribut atau sifat atau nilai dari orang, obyek atau kegiatan yang mempunyai variasi tertentu yang ditetapkan oleh peneliti untuk dipelajari dan kemudian ditarik kesimpulannya". Jenis penelitian ini menggunakan deskriptif kuantitatif, metode yang digunakan dengan teknik pengumpulan data menggunakan observasi dan tes, tes yang digunakan dalam penelitian ini adalah tes pengukuran kebugaran jasmani menurut (Lubis, 2016) Tes ini terdiri dari 5 item tes yaitu: tes kecepatan lari 20 meter, tes kemampuan kelincahan, tes kemampuan power tungkai, tes kemampuan kekuatan otot perut, tes lari 15 menit. Dalam penelitian deskriptif, peneliti tidak melakukan tindakan manipulasi atau memberikan perlakuan tertentu terhadap variabel atau merancang sesuatu yang diharapkan terjadi pada variabel, tetapi semua kegiatan, keadaan, kejadian, aspek, komponen atau variabel berjalan sebagaimana adanya (Sukmadinata, 2010). Penelitian ini variabel yang digunakan adalah profil kebugaran jasmani, populasi penelitian merupakan keseluruhan dari objek penelitian yang dapat berupa manusia, gejala, nilai, dan sebagainya. Sehingga objek-objek ini dapat menjadi sumber data penelitian (Siregar Syofian, 2013).

Populasi dalam penelitian ini adalah atlet pencak silat binaan Bank Sumsel Babel Palembang yang berjumlah 7 orang. Menurut (Arikunto, 2006), apabila subjek kurang dari 100, lebih baik diambil semuanya sehigga penelitiannya merupakan penelitian populasi Pengambilan sampel dilakukan dengan mengambil keseluruhan populasi 7 orang. Teknik analisis data dalam penelitian ini menggunakan metode analisis deskriptif persentase. yaitu pengolahan data seperti yang dikemukakan Maksun (Teguh Dwi Putranto et al., 2018) dengan cara frekuensi dibagi dengan total jumlah responden dikali 100 persen dengan rumus sebagai berikut : $\mathrm{P}=\frac{f}{N} \chi 100 \%$,

Keterangan: P : Persentase, F : Frekuensi, N : Jumlah Responden.

\section{HASIL}

Berdasarkan penelitian yang telah dilakukan pada atlet pencak silat binaan Bank Sumsel Babel Palembang, diperoleh pada hasil keseluruan tes kebugaran jasmani, krikteria yang mendominasi adalah baik dan sedang. Hal ini dibuktikan dengan ada 3 orang $(42,8 \%)$ kecepatan lari 20 meter berada dalam katagori Baik , ada 7 orang $(100 \%$ ) kelincahannya berada dalam katagori Sangat Baik, ada 6 orang ( 85,7\% ) power otot tungkainya berada dalam katagori Baik, ada 7 orang ( $100 \%$ ) kekuatan otot perutnya berada dalam katagori, ada 3 orang ( $42 \%$ ) daya tahannya berada dalam katagori Baik. 
Tabel 1. Distribusi Data Frekuensi Tes Lari 20 Meter

\begin{tabular}{cccc}
\hline Katagori & Kali & Frekuensi & Presentase \\
\hline SangatBaik & $<2,78$ & 2 & $28,5 \%$ \\
Baik & $2,32-2,76$ & 3 & $42,8 \%$ \\
Cukup & $2,76-316$ & 0 & $0 \%$ \\
Kurang & $>3,17$ & 2 & $28,5 \%$ \\
\hline
\end{tabular}

Berdasarkan tabel 1 dan gambar 2 diatas bahwa Tes Lari 20 Meter atlet pencak silat Binaan Bank Sumsel Babel Palembang diketahui atlet dalam ketegori sangat baik 2 orang $(28,5 \%)$, baik 3 orang (42,8\%), cukup 0 orang $(0 \%)$, dan kurang 2 orang $(28,5 \%)$.

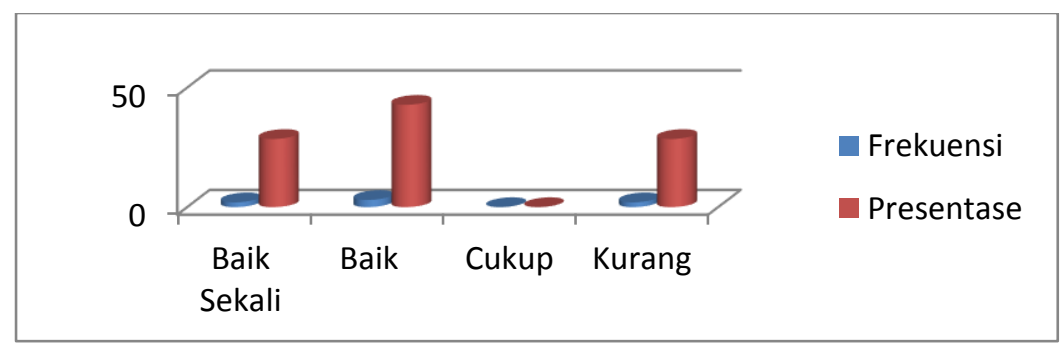

Gambar 2. Distribusi Data Frekuensi Tes Lari 20 Meter

Tabel 1. Distribusi Data Frekuensi Lari Bolak-Balik

\begin{tabular}{cccc}
\hline Katagori & Detik & Frekuensi & Presentase \\
\hline SangatBaik & $<12,1$ & 7 & $100 \%$ \\
Baik & $12,1-12,5$ & 0 & $0 \%$ \\
Cukup & $12,6-13,0$ & 0 & $0 \%$ \\
Kurang & $13,1-13,5$ & 0 & $0 \%$ \\
Kurangsekali & $>13,5$ & 0 & $0 \%$ \\
\hline
\end{tabular}

Berdasarkan tabel 1 dan gambar 2 di atas bahwa lari bolak-balik atlet pencak silat binaan Bank Sumsel Babel Palembang diketahui atlet dalam ketegori baiksekali 7 orang $(100 \%)$, kategori baik 0 orang $(0 \%)$, kategori sedang 0 orang $(0 \%)$, kategori kurang 0orang $(0 \%)$, dan kategori kurang sekali 0 orang $(0 \%)$. 


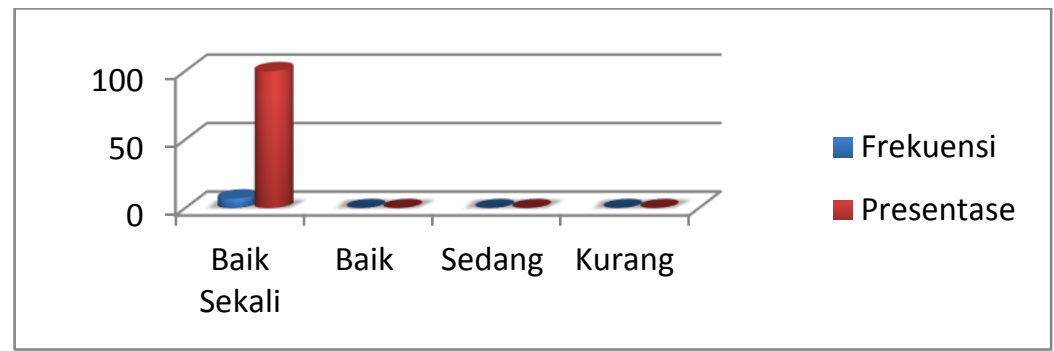

Gambar 2. Data Diagram Lari Bolak-Balik

Tabel 1. Distribusi Data Frekuensi Tiga Kali Lompat

\begin{tabular}{cccc}
\hline Katagori & Kali & Frekuensi & Presentase \\
\hline Sempurna & $>7.46$ & 0 & $0 \%$ \\
SangatBaik & $7.0-7.45$ & 0 & $0 \%$ \\
Baik & $6.0-6.99$ & 6 & $85,7 \%$ \\
Cukup & $5.0-5.99$ & 1 & $14,2 \%$ \\
Kurang & $<4.99$ & 0 & $0 \%$ \\
\hline
\end{tabular}

Berdasarkan tabel 1 dan gambar 2 di atas bahwa tiga kali lompat atlet pencak silat binaan Bank Sumsel Babel Palembang diketahui atlet dalam ketegori Sempurna 0 orang (0\%), kategori baik sekali 0 orang (0\%), kategori baik 6oran (85,7\%), kategori cukup 1 orang $(14,2 \%)$, dan kategori kurang 0 orang $(0 \%)$.

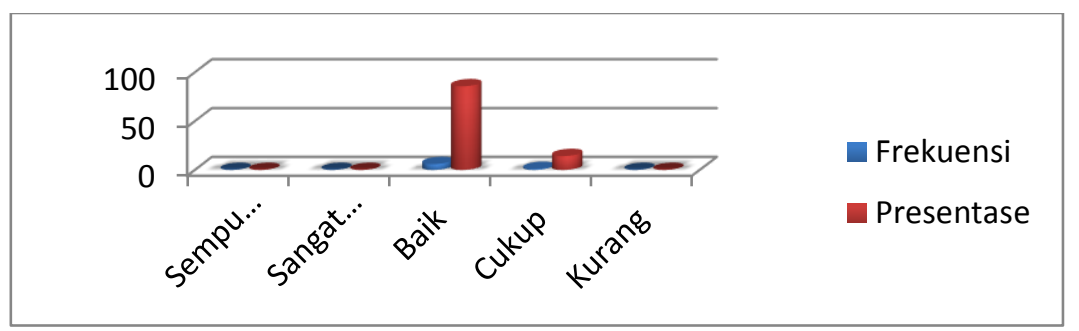

Gambar 2. Data Diagram Tiga Kali Lompat

Tabel 1. Distribusi Data Frekuensi Sit Up

\begin{tabular}{cccc}
\hline Katagori & Kali & Frekuensi & Presentase \\
\hline SangatBaik & $>41$ & 7 & $100 \%$ \\
Baik & $30-40$ & 0 & $0 \%$ \\
Cukup & $21-29$ & 0 & $0 \%$ \\
Kurang & $20-10$ & 0 & $0 \%$ \\
Kurangsekali & $<10$ & 0 & $0 \%$ \\
\hline
\end{tabular}

Berdasarkan tabel 1 dan gambar 2 di atas bahwa sit up atlet pencak silat binaan Bank Sumsel Babel Palembang diketahui atlet dalam ketegori sangat baik 7 orang (100\%), kategori baik 0 orang $(0 \%)$, kategori sedang 0 orang $(0 \%)$, kategori kurang 0 
orang $(0 \%)$, dan kategori kurang kurang sekali 0 orang $(0 \%)$.

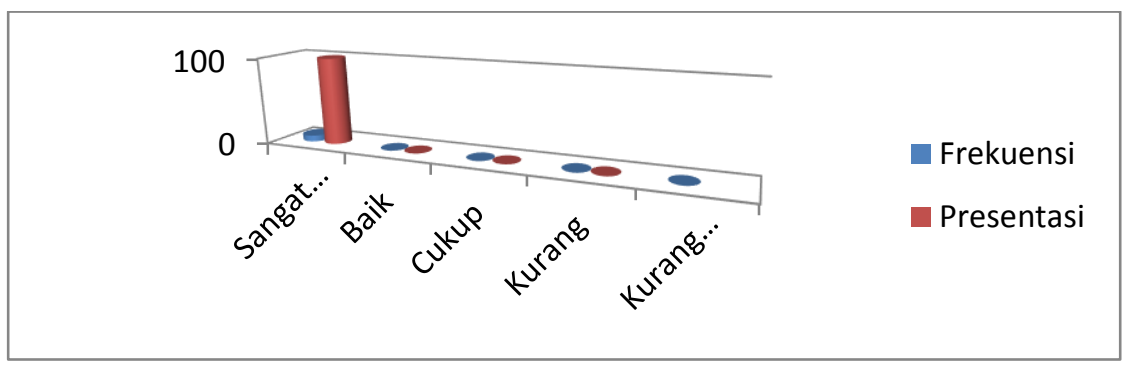

Gambar 2. Data Diagram Sit Up

Tabel 1. Distribusi Data Frekuensi Bleep Test

\begin{tabular}{llcl}
\hline \multicolumn{1}{c}{ Katagori } & \multicolumn{1}{c}{ Kali } & Frekuensi & Presentase \\
\hline SangatBaik & $>53$ & 1 & $14,2 \%$ \\
Baik & $43-52$ & 3 & $42,8 \%$ \\
Cukup & $34-42$ & 2 & $28,5 \%$ \\
Kurang & $25-33$ & 1 & $14,2 \%$ \\
Kurangsekali & $<24$ & 0 & $0 \%$ \\
\hline
\end{tabular}

Berdasarkan tabel 1 dan gambar 2 di atas bahwa Bleep Test atlet pencak silat binaan Bank Sumsel Babel Palembang diketahui atlet dalam ketegori baik sekali 1 orang (14,2\%),kategori baik 3 orang (42,8\%), kategori cukup 2 orang $(28,5 \%)$, kategori kurang 1 orang $(14,2 \%)$, dan kategori kurang sekali 0 orang $(0 \%)$.

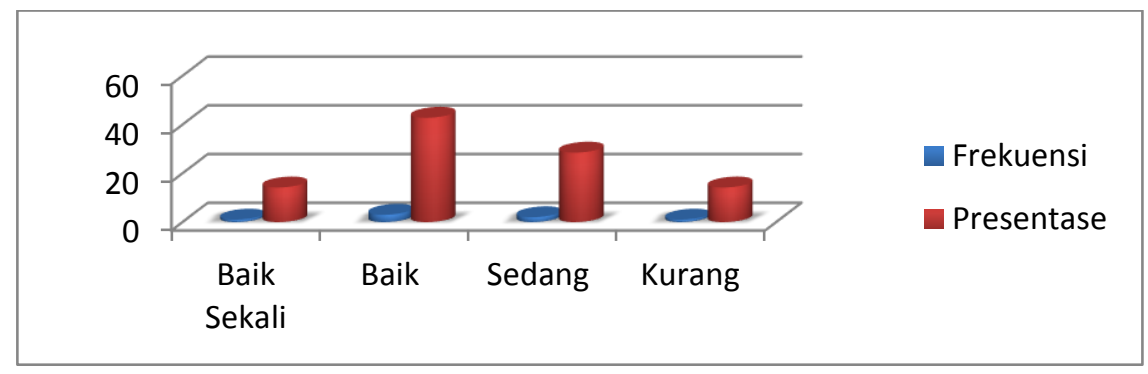

Gambar 2. Data Diagram Bleep Test

\section{PEMBAHASAN}

Berdasarkan hasil analisis data mengenai "Profil Kebugaran Jasmani Atlet Pencak Silat binaan Bank Sumsel Babel Palembang”, kebugaran jasmani atlet pencak silat binaan Bank Sumsel Babel Palembang masuk dalam katagori baik dan harus lebih ditingkatkan lagi, baik itu dari segi kecepatan, kelincahan, power otot tungkai, kekuatan otot perut, dan daya tahan. Kebugaran jasmani yang baik merupakan salah satu aspek penting yangharus dimiliki setiap atlet dalam seluruh cabang olahraga khususnya olahraga pencak silat. Prestasi yang maksimal dapat diraih apabila seorang atlet memiliki kebugaran jasmani yang baik, kebugaran jasmani merupakan salah satu unsur yang sangat penting dalam olahraga pencak silat oleh sebab itu, kebugaran jasmani 
harus berada dalam kondisi yang prima agar atlet bisa meraih prestasi yang maksimal dan kebugaran jasmani merupakan komponen utama yang harus dimiliki atlet agar atlet bisa meraih prestasi.

Menurut (Suharjana \& Purwanto, 2006) berpendapat bahwa "kebugaran jasmani dapat diartikan sebagai kesanggupan seseorang untuk menjalankan hidup sehari-hari tanpa menimbulkan kelelahan yang berlebihan dan masih memiliki kemampuan untuk mengisi pekerjaan ringan lainnya". Dengan demikian seorang atlet tidak akan dapat meraih prestasi yang maksimal apabila mempunyai kebugaran jasmani yang kurang baik, dapat diketahui bahwa kebugaran jasmani merupakan salah satu penunjang keberhasilan atlet meraih prestasi yang maksimal meskipun pada kenyataannya di lapangan masih ada atlet yang mempunyai kebugaran jasmani yang baik belum tentu mendapatkan prestasi yang maksimal pula, begitu juga sebaliknya diharapkan dengan tingkat kebugaran jasmani yang baik atlet dapat meningkatkan prestasi saat dalam menjalankan sebuah pertandingan sehingga mendapatkan hasil yang maksimal, apabila kebugaran jasmani yang dimiliki atlet kurang, maka dalam hal ini performa atlet tidak akan maksimal dan tidak akan bertahan lama dalam sebuah pertandingan, atlet akan mengalami kelelahan yang berlebihan sehingga akan kesulitan berfikir pada saat bertanding, mudah dibanting, mudah putus asa, dan hal-hal lain yang membuat atlet tersebut mengalami kekalahan pada saat bertanding. Oleh sebab itu seorang atlet harus tetap menjaga pola makan maupun minum mereka karna itu adalah pokok utama dalan kebutuhan seorang atlet atau olahragawan, kebugaran jasmani merupakan salah satu yang perlu ditingkatkan karna ketika latihan dalam waktu yang lama, penggantian cairan dalam tubuh hanya dengan air tidak cukup, karena air tidak menggantikan cairan elektrolit yang hilang bersama keringat, maka sebagai atlet harus bisa menjaga tubuh tetap terhidrasi agar tidak berpengaruh pada performa atau prestasi atlet (Mila Pita K., 2017).

\section{KESIMPULAN}

Berdasarkan hasil yang diuraikan pada hasil penelitian dan pembahasan di atas dapat disimpulkan bahwa Profil kebugaran jasmani atlet pencak silat binaan Bank Sumsel Babel Palembang pada tingkat kebugaran jasmani mereka di katagorikan Baik. untuk meningkatkan kebugaran jasmani atlet pencak silat pada Bank Sumsel Babel Palembang disarankan untuk tetap kontinyu pada latihan mereka sehingga kebugaran mereka tetap terjaga dan stabil. Untuk peneliti selanjutnya disarankan untuk lebih mendalami pada penelitian ini.

\section{DAFTAR PUSTAKA}

Amanah, m. (2015). Tingkat kebugaran jasmani siswa smp negeri 5 palembang. Universitas persatuan guru republik indonesia.

Amrullah ramdani. (2015). Pengaruh latihan training resistense xander terhadap kemampuan tendangan sabit pencak silat. In jurnal pendidikan olahraga (vol. 
4, issue 1).

Arikunto, s. (2006). Prosedur penelitian suatu pendekatan praktik. Rineka cipta.

Astawa, i. M. Y., astra, ik. B., \& suwiwa, i. G. (2017). Pengembangan media pembelajaran teknik dasar kuda-kuda pencak silat dengan kartu bergambar. In jurnal pendidikan jasmani, olahraga dan kesehatan undiksha (vol. 5, issue 2).

C. Tri juni, p. (2012). Profil kondisi fisik atlet anggar di kabupaten purworejo jawa tengah.

Gus hendri, \& aziz, i. (2020). Motivasi siswa dalam proses pembelajaran pendidikan jasmani olahraga kesehatan. Jurnal patriot, 2(1), 171-181.

Hartati, h., destriana, d., \& junior, m. (2019). Latihan dot drill one foot terhadap kelincahan tendangan sabit dalam ekstra kurikuler pencak silat. Altius: jurnal ilmu olahraga dan kesehatan, 8(1).

Hilman, m. (2016). Profil kondisi fisik pemain sepakbola perkumpulan sepak bola universitas negeri yogyakarta.

Kriswanto, e. S. (2015). Pencak silat (pustaka baru press (ed.)).

Lubis, j. (2016). Pencak silat edisi ketiga (ketiga). Rajawali sport.

Mila pita k. (2017). Analisis tingkat dehidrasi atlet pencak silat pplpd kota madiun universitas negeri surabaya - neliti. Jurnal prestasi olahraga.

Octavia, haningtyas nur, \& mardela, r. (2019). Pengaruh latihan kelincahan terhadap kemampuan tendangan sabit atlet pencak silat kuciang putiah harimau campo. Jurnal patriot, 1(1), 145-150. Https://doi.org/10.24036/patriot.v1i1.168

Ramdani muksin, barlian eri, \& rawadi hendri. (2020). Kondisi fisik atlet pencak silat. Jurnal patriot, 2(4), 966-981.

Ratna, p. (2013). Tingkat kebugaran jasmani menurut tes kebugaran jasmani indonesia atlet putri usia 13-15 tahun klub bola voli ganevo yogyakarta.

Septa bayu, triaiditya martaviano, setyaningsih puji, \& farhanto galih. (2018). Studi biomekanika posisi kuda-kuda tengah pada bela diri pencak silat. In prosiding seminar nasional iptek olahraga (vol. 1, issue 4).

Siregar syofian. (2013). Open library - metode penelitian kuantitatif: dilengkapi dengan perbandingan perhitungan manual \& spss.

Sugiyono. (2010). Metode penelitian pendidikan pendekatan kuantitatif, kualitatif, dan $r \& d$. Alfabeta.

Suharjana, \& purwanto, h. (2006). Kebugaran jasmani mahasiswa d ii pgsd penjas fik uny. In jurnal pendidikan jasmani indonesia (vol. 5, issue 2). 
Sukmadinata, n. S. (2010). Metode penelitian pendidikan. Bandung. Pt remaja rosdakarya.

Teguh dwi putranto, fifit yet wulandari, \& aghus sifaq. (2018). Profil kondisi fisik atlet panahan gresik. Jses : journal of sport and exercise science, 1(1), 20. 